\title{
ESTUDIO DE UN CASO: EL DÍA DE LA HISPANIDAD Y LA NORMATIVA DEL ESPAÑOL
}

\section{A CASE STUDY: COLUMBUS DAY AND REGULATIONS OF THE CASTILIAN}

\section{AUTORA}

\section{Beatriz Peña Acuña}

Profesora ayudante. Universidad Católica San Antonio. Murcia (España)

bpena@pdi.ucam.edu

\section{RESUMEN}

El objetivo de esta disertación es aportar una perspectiva histórica: mostrar la realidad de conciencia de pertenencia a Hispanoamérica con relación al origen colonial español a través de un medio de comunicación. Para llevar a cabo tal objetivo se realiza un estudio de un caso: se analiza la cobertura del día de la Hispanidad y un estudio sincrónico del castellano de un periódico mexicano digital, Notiaranas, de esa ciudad.

Para comenzar, este artículo pretende dar una retrospectiva histórico-geográfica de Aranas, una ciudad media mejicana.

En segundo lugar, el planteamiento metodológico de estudio de caso sirve de punto de referencia, aunque restringido a este caso, para conocer de qué modo práctico un periódico local celebra el día de la Hispanidad. El estudio lingüístico a nivel sincrónico nos muestra el estadio actual de la lengua y a nivel diacrónico muestra la evolución de la 
lengua respecto a la norma del castellano. Para ello se tiene en cuenta el estadio de la oficialidad del castellano en México.

Además como metodología se realiza una investigación histórica acerca de los eventos del día de la Hispanidad previstos ese día en la capital y que supuestamente tienen que ser difundidos por los periódicos locales.

En concreto se analizan cuatro secciones del periódico desde un punto lingüístico sobre el uso del castellano y además se tiene en cuenta la repercusión informativa del Día de la Hispanidad analizada desde un punto de vista lingüístico y asimismo de tratamiento de contenido periodístico. Las secciones que se pretenden estudiar son: Sección internacional (Naciones), Sección Nacional (México), Sección Local (Arandas) y Anuncios.

\section{PALABRAS CLAVE}

Historia - Día de la Hispanidad - Estudio de caso - periódico digital - oficialidad castellano

\section{ABSTRACT}

The objective of this dissertation is historical: the reality shows or not consciousness of belonging to Latin America in relation to the Spanish colonial origins through the Media. To accomplish this objective is a study of a case: an analysis of the coverage of Columbus Day and a synchronic study of the Castilian of digital "Notiaranas", a Mexican newspaper in that city.

To begin, this article is to provide a historical retrospective Geographic Aranas, a Mexican city.

Second, the methodological approach of case study serves as a benchmark, albeit restricted, to know how practical a local newspaper celebrates Columbus Day. The 
synchronic linguistic study at this stage shows the diachronic level language and shows the evolution of language over the Castilian rule. This will take into account the stage of the official Castilian in Mexico.

Also as a methodology it is performed historical research about the events planned Columbus Day that day in the capital and who are supposed to be distributed by local newspapers.

In particular, we analyze four sections of the paper from a linguistic point about the use of Castilian, and also taking into account the impact through the Columbus Day analyzed from a linguistic point of view and also for journalistic treatment. The sections that will be studied are: International Section (UN), National Section (Mexico), Section Local Section and Announcements.

\section{KEY WORDS}

History - Columbus Day - Case study - digital newspaper - official Castilian

\section{ÍNDICE}

1. Introducción

1.1. Contexto histórico-geográfico de Aranas

1.2. Hitos legales de la oficialidad del castellano en México

1.3. Celebración del Día de la Hispanidad en Madrid y otras capitales hispanas

2.- Estudio lingüístico

3.- Conclusiones

4.- Bibliografía 


\section{Introducción}

Este estudio pretende un conocimiento sincrónico a través de un análisis léxico y morfosintáctico de cuatro noticias de cuatro secciones de un periódico digital como estudio de caso del uso del castellano en la prensa latina. Además se observa el tratamiento que hace la rotativa del día de la Hispanidad para descubrir las actitudes de la rotativa al respecto y de algún modo descubrir el nivel de difusión de una conciencia de pertenencia antigua colonial.

El periódico digital del que se ocupa este estudio se llama Notiarandas ${ }^{1}$. Es una publicación de un municipio denominado Arandas, en el estado de Jalisco, México. El nombre del periódico es un nombre compuesto de noticia y Aranda para vincularse a esta población. Han hecho la composición de forma que se reconoce noticia de forma coloquial y se pone de relieve Arandas.

\subsection{Contexto histórico-geográfico de Aranas}

El municipio de Arandas está situado en la Región Altos Sur del Estado de Jalisco, a $140 \mathrm{Km}$. al este de la ciudad de Guadalajara. Es un municipio de alrededor 80.000 habitantes. Originariamente estuvo poblada por pueblos tarascos y chichimecos. La población se dedica alrededor del $22 \%$ al sector primario, el $37 \%$ al sector secundario y el $39 \%$ al sector terciario. Las principales actividades económicas son la agricultura, ganadería, minería, industria, comercio, servicios y transporte ${ }^{2}$. Así pues, la nación elegida para este estudio es México. Se trata de la nación hispanohablante más poblada con casi 107 millones de habitantes. La forma de gobierno es una República Federal desde 1824 formada por 32 entidades

\footnotetext{
${ }^{1}$ http://www.notiarandas.com/ [acc: 16.10.2008]

${ }^{2}$ http://www.arandas.gob.mx/ [acc:11.11.2008]
} 
federativas. Cada uno de los estados es libre y soberano. Es un país extenso con 1.984.375 km situado en Norteamérica. Es un país colindante con EE.UU., con Guatemala y con Belice. La moneda es el peso. Por el volumen de su producto interno bruto, se sitúa en la decimocuarta economía mundial, pero hay mucha desigualdad entre los municipios ${ }^{3}$.

\subsection{Hitos legales de la oficialidad del castellano en México}

Sobre la oficialidad del español, se han consultado varias fuentes. Se encontró una enciclopedia digital que afirmaba que el español era la lengua oficial ${ }^{4}$. Se considera en esta investigación que este dato es incorrecto. Se encontró otra fuente que comentaba que la Constitución mexicana no especificaba nada sobre el español u otra como oficial. Argumentaba además que la Ley General de Derechos Lingüísticos de los Pueblos Indígenas del 2001 en el artículo séptimo indicaba que cualquiera de las 64 lenguas indígenas contenía el mismo valor para gestionar trámites. Por lo tanto, el español poseía el mismo valor que las demás lenguas indígenas. Informaba sobre el uso del español como lengua materna del $97 \%$ de la población ${ }^{5}$.

Otra fuente confirmaba esta anterior ${ }^{6}$. Añadía que desde 1992 la Constitución mexicana denominaba a la nación como "pluricultural", y que a partir del 2005 el gobierno oficializó la traducción del himno nacional a las lenguas indígenas. En otro artículo se afirmaba que el español se trata de la lengua nacional porque forma parte del patrimonio cultural nacional ${ }^{7}$.

\footnotetext{
${ }^{3}$ http://es.wikipedia.org/wiki/M\% C3\% A9xico [acc: 11.11.2008] datos del 1-7-2008

${ }^{4}$ http://enciclopedia.us.es/index.php/M\% C3\% A9xico [acc: 11.11.2008]

${ }^{5}$ http://maquinarespuestas.blogspot.com/2008/03/es-cierto-que-mxico-no-tiene-lenqua.html [acc:11.11.2008]

${ }^{6}$ http://wapedia.mobi/es/Lenguas_de_M\% C3\% A9xico [acc: 11.11.2008]

${ }^{7}$ http://www.highbeam.com/doc/1G1-137003356.html [acc:11.11.2008]
} 
El periódico se mostraba idóneo, pues presentaba las secciones que se pretendían estudiar Sección internacional (Naciones), Sección Nacional (México), Sección Local (Arandas) y Anuncios.

El habla jalisciense se considera una subdivisión complementaria dentro de la división de diez regiones que Lope Blanch establece en su artículo sobre México ${ }^{8}$.

El periódico omite el día 12, día de la Hispanidad cualquier noticia sobre el acontecimiento, en cambio publica el día anterior un capítulo de la historia del municipio que se ha estudiado. Se titula "La piedra en el zapato" escrito por un escritor invitado. La historia que relata está en tono satírico y critica una etapa cacique que perjudica al pueblo en su comercio con los "gringos".

\subsection{Celebración del día de la Hispanidad en Madrid y otras} capitales hispanas.

Recordamos que "El Día de la Hispanidad" o también llamada "Fiesta Nacional de España" conmemora la efeméride histórica del Descubrimiento de América por parte de Cristóbal Colón y los Reyes Católicos tras la firma de las Capitulaciones de Santa $\mathrm{Fe}$.

La celebración tiene lugar cada 12 de octubre en la ciudad de Madrid, donde se celebra un desfile militar al que asisten el Rey junto a la Familia Real y los representantes más importantes de todos los poderes del Estado, además de la mayoría de los presidentes de las autonomías españolas. En las capitales hispanas de

\footnotetext{
8 LOPE BLANCH, Juan M.(1996) : “México”. En ALVAR, M. (1996): Manual de dialectología hispánica. El español de América. Ariel. Barcelona. pág. 88
} 


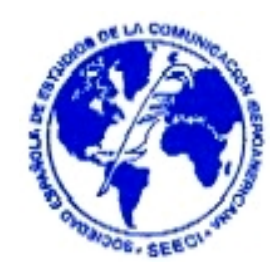

Iberoamérica también se celebra una conmemoración con varios eventos programados.

El Descubrimiento de América en 1492 fue trascendental y el 12 de octubre se ha considerado como un día memorable porque, a partir de entonces, se inició el contacto entre Europa y América, que transformó las visiones del mundo y las vidas tanto de europeos como de los nativos americanos, ya que a partir de este momento se gesta la dominación europea en América.

\section{Estudio lingüístico}

A) Sección internacional

En la Sección Internacional descubrimos varios aspectos de interés:

A.1.) Nivel ortográfico:

- $\quad$ Televidententes (error ortográfico en vez de televidentes)

- Estadunidense uso extendido en vez de estadounidense que es el uso en México. Eso puede levantar la sospecha de que la noticia pertenece a una agencia internacional. Además las noticias están bien redactadas con un español estándar y sin mejicanismos.

A. 2) Nivel morfosintáctico:

- Más-menos (construcción en composición en vez de la expresión más o menos). 
A pregunta expresa de qué aprendieron omisión del verbo cuando les hicieron la pregunta expresa.

- $\quad$ Al ser excluyente con el conjunto y la imposibilidad de poder tomar decisiones error sintáctico en vez de al ser excluyente con el conjunto e imposibilitar la toma de decisiones.

- Obama aventaja a McCain por cuatro puntos con 51 por ciento de las preferencias contra, uso erróneo de la preposición en vez de "frente".

A.3) Nivel léxico:

Encuestadora (adjetivo sustantivado en vez de empresa que ofrece servicios de encuestas o estudios de investigación de marketing)

- $\quad$ Televidentes (en vez de espectadores)

- Desempeño según el diccionario de la Real Academia de la Lengua (DRAE) significa acción y efecto de desempeñar o desempeñarse. Desempeño está en desuso.

- $\quad$ Reporte según la DRAE noticia, informe. Reporte está en desuso.

B) Día de la Hispanidad

En cuanto al artículo con referencia al día de la Hispanidad "La piedra en el zapato" encontramos las siguientes características:

B.1) Nivel ortográfico:

Pinas en vez de piñas.

Por que en vez del causal porque Dios nunca olvida.

B.2) Nivel morfosintáctico: no aparecen incidencias notables. 
B.3) Nivel léxico:

- Mundo universo composición usada con sentido irónico referida a una localidad sobre la que acaecen muchas dificultades.

- Había fungido en el diccionario DRAE significa desempeñar un empleo o cargo, sin embargo, el término está en desuso.

- $\quad$ Fronteras del rededor según la DRAE significa contorno o redor, sin embargo está en desuso en el español y se utiliza más el término alrededor.

- Gringos vocablo despectivo utilizado para los norteamericanos. En el DRAE explica que en la América meridional se aplica a estadounidense.

- $\quad$ Puercos aparece en la DRAE significa cerdo (animal)

- $\quad$ Dizque en vez de di que es una expresión usual mexicana

- Erario en el texto se refiere a lo recaudado por Hacienda, en el diccionario DRAE erario se refiere directamente a Hacienda

- Convocaron a la raza en sentido figurado a la humanidad que allí había, a los componentes de ese municipio, a los del pueblo.

- Llamado según la DRAE llamamiento que tiene un uso más común que el primero.

- Bola de putos insulto referido a una cantidad de hombres

- Bacha no se encuentra el término en los diccionarios DRAE. En una página web encontramos el significado ${ }^{9}$. Se trata de un término de jerga referido a colilla de cigarro de marihuana.

- $\quad$ Tendajones referido a tiendas, no aparece en los diccionarios de la DRAE

- Zopilotes significa buitre mexicano, aquí está aplicado con sentido figurativo como insulto

\footnotetext{
${ }^{9}$ http://www.jergasdehablahispana.org/index.php?pais=M\% E9xico\&palabra=bacha6ti [acc: 19.11.2008]
} 
- Noqueaban anglicismo que viene de knock out según la DRAE derrotar, imponerse sobre alguien rápida o notablemente

- Puro vándalo chicano uso del adjetivo puro con sentido enfatizador en el uso mejicano

- Chacalote error por cachalote o palabra inventada entre chacal y la terminación-ote

- Llevaron flores y mariachis al santuario luego de cinco días de peregrinación a pata con sentido de después, sería un uso más normal encontrar aquí después

C) Sección Nacional

En referencia a la Sección Nacional observamos varios elementos:

La redacción de la segunda noticia es correcta y en un español estándar.

C.1) Nivel ortográfico:

\section{c.1.1.) Noticia primera}

- $\quad$ Son políticas anticiclicas son instrumentos que tenemos a nuestra disposición. Falta de puntuación, de una coma o punto, también en la palabra esdrújula: anticíclicas

- Obligacions en vez de obligaciones

- Si pasaremos por un periodo falta la coma, omisión del signo de puntuación 
C.2.) Nivel morfosintáctico:

\section{c.2.1.) Noticia primera}

Error en el uso del nexo comparativo mayores a las esperadas en vez de mayores que las esperadas.

- $\quad$ Luego de que: queísmo

- Lo anterior. enlace incorrecto referido al anterior párrafo

\section{c.2.2.) Noticia tercera}

- Error de concordancia Proponen PAN registro de empleados de empresas de seguridad en vez de "PAN propone"

\section{c.2.3.) Noticia cuarta}

- A los profesores que incurran en condicionamiento para inscribir a niños queda poco clara esta expresión con una expresión final en vez de incurran "en condicionamiento a la hora de inscribir", queda más claro con una expresión temporal

C.3) Nivel léxico:

\section{c.3.1.) Noticia primera}

- $\quad$ Medidas que se pueden instrumentar significado en desuso que lo considera la RAE: crear, constituir, organizar

Checar la capacidad: significa comprobar. La RAE dice que en México se utiliza más chequear que es una copia del inglés to check 
4.0 y 2.0 en vez de $4 \%$ y $2 \%$

c.2.2) Noticia segunda

- $\quad$ En el uso de Acrónimos en el título no se explica a qué se refiere SSA (quizás Secretario de Salud) y UE parece ser que es Eagle Pass

\section{c.3.3.) Noticia tercera}

- Laboran en vez de trabajan puede tratarse de un latinismo o un italianismo - Fue turnada según la RAE uso en Méx. En uso jurídico y administrativo, remitir una comunicación, expediente o actuación a otro departamento, juzgado, sala de tribunales, funcionario, etc. en vez del verbo intransitivo turnar

Dictaminación para formarse sigue la ley analógica de formación de sustantivos en vez de dictamen

\section{c.3.4.) Noticia cuarta}

- Pesos moneda nacional mexicana Plantel: según la RAE en Méx. Significa "escuela, establecimiento público para enseñanza infantil”.

D) Sección local.

En lo que respecta a la Sección Local advertimos varias incidencias:

D.1.) Nivel ortográfico:

- En la noticia sobre el PRI es frecuente la omisión de comas como falta de puntuación por ejemplo San Ignacio Cerro Gordo Jalisco. 
D.2.) Nivel morfosintáctico:

- Los manda felicitar en vez de les manda saludos o les envía saludos

- Más fuerte llovía se antepone la función circunstancial al verbo

- $\quad$ A un mes iniciada en vez de a un mes de iniciarse

- $\quad$ No es de dudarse en vez de no se puede dudar, no es posible dudar

\section{d.2. 1) Cuarta noticia}

Que se planteó para tres años en vez de se planteó para que durara tres años, hay una elipsis del verbo

- $\quad$ Se planteó originariamente a dos etapas en vez del uso de la preposición "en", en dos etapas

- De acuerdo al titular en vez de de acuerdo "con" el titular

- Pesos a ejercer queda poco clara esta expresión aunque ejercer pueda significar según la RAE hacer uso de un derecho, capacidad o virtud.

D.3) Nivel léxico:

- Sinvergüenzadas en vez de hechos deshonestos, han sustantivado el adjetivo - Regidores cargo, palabra en desuso en el castellano frecuente referido a concejal

- Expresión se dio tiempo para convivir en vez de se permitió tiempo para conversar

- $\quad$ Evento en dos ocasiones en vez de suceso, acontecimiento. Según el DRAE en Méx., Perú, Uruguay y Venezuela referido a suceso importante y programado, de índole social, académica, artística o deportiva.

Señalamientos viales por señales de tráfico 
Cercas por vallas, el uso de cerca en la RAE se reconoce sólo referido al adverbio

- Extrañan, está en desuso se utiliza más echar de menos

- Planeación por planificación

- 50 metros de concreto según la DRAE concreto puede significar adj. Sólido, compacto, material. En ese caso esta sustantivado, convertido en nombre el adjetivo.

- $\quad$ Atascadero según la Real Académica de la Lengua Española se trata de lodazal o sitio donde se atascan los carruajes, las caballerías o las personas. Está en desuso en España.

- Parte oriente en vez de parte oriental

- Colector. según la DRAE caño o canal que recoge todas las aguas procedentes de un avenamiento o las sobrantes del riego.

- Haciéndola más tardada

- Carretera de carga pesada

\section{D.3.1.) Cuarta noticia}

- Faldones del inmueble se entiende que es la parte baja del inmueble con sentido figurativo, no aparece en los diccionarios de el DRAE

Reubicación con sentido general según el DRAE que se utiliza en América de situar o instalar en determinado espacio o lugar

- Reportando significado con el matiz de uso general según la RAE de alcanzar, conseguir, lograr, obtener en vez del uso americanista de transmitir, comunicar, y dar noticia. 
E) Anuncios.

En la sección de Anuncios descubrimos varios componentes interesantes:

E.1) Nivel ortográfico:

- $\quad$ No pone entre comillas el nombre del curso Inteligencia Emocional.

- En el anuncio joven empresariom de Guadalajara hay muchos errores ortográficos como empresariom por empresario, facinaron pos fascinaron, volver air (en vez de a ir), acer por hacer, ricarod por Ricardo, ami en vez de a mí; no tiene en cuenta los signos de puntuación y todas las palabras las escribe en minúscula.

\section{E.2.) Nivel morfosintáctico:}

- Comenzando uso del gerundio inapropiado sin verbo de acción anterior quizás por la redacción telegramática del anuncio.

- Que ingreses a la compañía: en vez de que ingreses en la compañía.

- Te concertamos una cita el verbo mientras lo correcto es podrás concertar una cita con nosotros o te concederemos una cita, quizás copiado del significado de la expresión anglosajona / have an appointment, tengo una cita, con sentido de posesividad.

E.3) Nivel léxico:

- Snack attack, nuggets (tres palabras inglesas), hawaianas (copia del inglés referido a hamburguesas hawaianas con carne y piña).

- $\quad$ Allende (significa más allá de-normalmente locución preposicional aquí se ha sustantivado). 
- $\quad$ Res (en México significa animal vacuno frente al significado normativizado del $\operatorname{DRAE}^{10}$ : Animal cuadrúpedo de ciertas especies domésticas, como del ganado vacuno, lanar, etc., o de los salvajes, como venados, jabalíes, etc.).

- Estacionamiento se utiliza en español por lo general pero quizás sea más frecuente hablar de aparcamiento (que viene de la palabra inglesa to park).

- Egresados no aparece ni en la RAE de la lengua española ni en la panhispánica, tiene relación con la palabra inglesa graduated (graduado), copia de la palabra inglesa.

- $\quad$ Prospectadores y reclutadores: formación derivada del verbo para la formación del adjetivo que aquí ejerce una función sustantiva.

- $\quad$ Proactivo: copia del inglés proactive.

- $\quad$ Barrido: el sentido es correcto pero está tomado en sentido figurado de tener el control de las calles que se han recorrido

\section{Conclusiones}

PRIMERA. El apartado de noticias internacionales se sospecha que pueda provenir de una agencia de noticias extranjera. No tiene apenas errores y tiene pocas incidencias, en total nueve.

SEGUNDA. El artículo con referencia al día de la Hispanidad no tiene apenas faltas de ortografía, ninguna en el nivel morfosintáctico, sin embargo tiene muchas incidencias en el nivel léxico, diecisiete, con mejicanismos y una palabra que pertenece a la jerga.

TERCERA. El apartado de noticias nacionales tiene tres errores ortográficos, muchas incidencias morfosintácticas, cinco, y se incrementa el número de incidencias a nueve en el nivel léxico.

\footnotetext{
${ }^{10}$ http://buscon.rae.es/drael/SrvltConsulta?TIPO BUS=3\&LEMA=res [acc:17.11.2008]
} 
CUARTA. La sección de noticias locales tiene un error ortográfico, un número considerable de incidencias morfosintácticas, ocho, y se incrementa el número de incidencias a diecisiete en el nivel léxico.

QUINTA. El apartado de anuncios tiene muchos errores ortográficos, siete, un número discreto de errores morfosintácticos, tres, y un número de incidencias considerable, ocho, en el nivel léxico.

SEXTA. La sección con mayor número de error ortográfico ha sido el apartado de anuncios que muestra la evolución mayor de la lengua hablado. El apartado con mayor número de errores sintácticos ha sido el apartado de noticias locales, se destaca el mal uso de las preposiciones y las copias sintácticas del inglés. El apartado con mayor número de incidencias a nivel léxico ha sido el artículo anterior al día de la Hispanidad y el apartado de noticias locales con mejicanismos.

SÉPTIMA. En este caso que estudiamos -conclusión menor- estimamos que el hecho de que no haya aparecido ninguna noticia sobre el día 12, Día de la Hispanidad, implica que este periódico no le concede ningún valor a esa memoria, no lo estima de interés y no lo considera noticia. Se podría estipular que detrás de esta omisión puede subyacer una talante insensible o incluso de desaprobación desde la dirección del medio hacia sus orígenes históricos, la colonización española, etc. De este modo, este diario, en concreto, no hace difusión de una conciencia de pertenencia al origen cultural colonial español.

\section{Bibliografía}

ALVAR, Manuel. (1996): Manual de dialectología hispánica. El español de América. Ariel. Barcelona. 
CASADO VELARDE, M. (2000): El castellano actual: usos y normas. [7ª̣]. EUNSA. Pamplona.

GÓMEZ TORREGO, L. (1989): Manual de español correcto. Arco/Libros, 2 vols. Madrid.

GÓMEZ, J. P. (2003): Lengua. Sistema y comunicación. Universidad Católica San Antonio, 2003. Murcia.

GÓMEZ TORREGO, L. (1992): El buen uso de las palabras. Arco/Libros. Madrid.

GÓMEZ TORREGO, L. (1996): Gramática didáctica del español. Santillana. Barcelona.

MARCOS MARÍN, F.: "La lengua española en Internet", en Anuario del Instituto Cervantes.

MARTíN VIVALDI, G. (2002): Curso de redacción. Teoría y práctica de la composición y del estilo. Paraninfo. Madrid.

REAL ACADEMIA ESPAÑOLA. (1999): Ortografía de la lengua española. Espasa-Calpe. Madrid.

REAL ACADEMIA ESPAÑOLA. (2001): Diccionario de la lengua española. [22a ${ }^{a}$.Espasa-Calpe. Madrid.

ROMERO GUALDA, Ma V. (1996): El español en los medios de comunicación. Arco/Libros. Madrid. 
ROMERO GUALDA, Ma V. (Coord) (2002): Lengua española y comunicación. Ariel. Barcelona.

SECO, M. (1999): Diccionario de dudas y dificultades de la lengua española. [ed. rev. y aum.]. Espasa-Calpe. Madrid.

\section{Webgrafía}

Enciclopedia libre universal http://enciclopedia.us.es/index.php/M\% C3\% A9xico [acc: 11.11.2008]

Máquina respuestas blog

http://maquinarespuestas. blogspot.com/2008/03/es-cierto-que-mxico-no-tienelengua.html [acc:11.11.2008]

High beam

http://www.highbeam.com/doc/1G1-137003356.html [acc:11.11.2008]

Wapedia

http://wapedia.mobi/es/Lenguas_de_M\% C3\% A9xico [acc:11.11.2008]

Enciclopedia Wikipedia

http://es.wikipedia.org/wiki/M\% C3\% A9xico [acc:11.11.2008]

Gobierno de Arandas

http://www.arandas.gob.mx/ [acc: 11.11.2008] 
Peña Acuña. Beatriz (2008): Estudio de un caso: el Día de la Hispanidad y la normativa del español. No 17. Noviembre. Año XII. Páginas: 77-96

ISSN: 1576-3420 DOI: http://dx.doi.org/10.15198/seeci.2008.17.77-96

Portal J ergas de habla hispana

http://www.jergasdehablahispana.org/index.php?pais=M\%E9xico\&palabra=bacha6ti [acc: 19.11.2008] 